\title{
Olhar histórico do português brasileiro através do gênero lírico: contribuições de análises advindas das Cantigas de Santa Maria
}

DOl: http://dx.doi.org/10.21165/el.v49i1.2577

\section{Gisela Sequini Favaro'}

\section{Resumo}

O presente artigo consiste em ressaltar a importância do gênero lírico para os estudos historiográficos da língua, em especial, o emprego das Cantigas de Santa Maria (CSM) para os estudos linguísticos. Segundo Mattos e Silva (1989, p.15), o lugar de produção coincide com os limites históricos em que o português era usado como língua escrita - e isso não se restringe aos limites da nação portuguesa, como se sabe - e os informantes são os produtores dos documentos que, elaborados naqueles limites cronológicos, chegam até o pesquisador atual. Desejamos demonstrar as contribuições do gênero lírico (em especial, da lírica religiosa) para a observação das mudanças linguísticas pelas quais o português passou no decorrer de sua constituição, com destaque para as formas verbais imperativas. Assim, visamos mostrar que a retomada de fatos do passado linguístico da língua portuguesa pode trazer uma maior compreensão da estrutura do português atual.

Palavras-chave: gênero lírico; cantigas medievais; história do português.

1 Universidade Estadual Paulista "Júlio de Mesquita Filho" (UNESP), Araraquara, São Paulo, Brasil; giselasfavaro@gmail.com; https://orcid.org/0000-0002-7321-7935. 


\title{
An historical view to Brazilian Portuguese through the lyrical genre: contributions from Cantigas de Santa Maria analysis
}

\begin{abstract}
This article emphasizes the importance of the lyric genre for the historiographical studies of the language, especially the use of Cantigas de Santa Maria (CSM) for the linguistic studies. According to Mattos e Silva (1989, p.15), the place of production matches with the historical limits in which Portuguese was used as a written language - and this is not restricted to the limits of the Portuguese nation, as we know - and the informants are those who produced the documents elaborated within those chronological limits and reached the current researcher. We want to present the contributions of the lyric genre (especially religious lyricism) to observe the linguistic changes that Portuguese has undergone in the course of its formation, with emphasis on the imperative verb forms. Thus, we aim to show that the resumption of facts from the linguistic past of bilingual Aviation the Portuguese language can bring a greater understanding of the current Portuguese structure.
\end{abstract}

Keywords: lyric genre; medieval songs; Portuguese history.

\section{Introdução}

Segundo Marcuschi (2008), a riqueza e a diversidade dos gêneros textuais são amplas e inesgotáveis, visto que esses são entidades, permeadas por fenômenos históricos vinculados à vida cultural e social, cuja função é contribuir para ordenar e estabilizar as atividades comunicativas. Para o autor, a circulação dos gêneros textuais na sociedade é um dos aspectos mais fascinantes, pois revela como a própria sociedade se organiza em todos os seus aspectos. Os gêneros são a manifestação mais visível do funcionamento que eles ajudam a constituir, envolvendo crucialmente a linguagem, as atividades enunciativas e as intenções, por exemplo. Logo, desde tempos mais remotos, estão presentes em situações comunicativas e não há comunicação que não seja feita através de algum gênero. Neste sentido, pretendemos refletir como a lírica medieval portuguesa pode trazer contribuições relevantes para os estudos linguísticos.

\section{Textos e Manuscritos Medievais}

Na época medieval, a arte de trovar se constituía em uma atividade sociocultural e se concretizava, textualmente, por cantigas. As cantigas religiosas, juntamente com as de amor (canto em voz masculina), de amigo (canto em voz feminina) e de escárnio e maldizer (cantiga satírica, respectivamente com ou sem equívoco), são os principais gêneros da poesia galego-portuguesa. Assim, as poesias trovadorescas galego-portuguesas são um dos patrimônios mais ricos da Idade Média peninsular, produzidas durante o período, genericamente, de finais do século XII a meados do século XIV. 
Mattos e Silva (2006, p. 22), ainda sobre o período de datação das primeiras cantigas medievais, afirma que, "entre os fins dos séculos XII e XIII, as cantigas circulavam na tradição oral e, pode-se admitir, em folhas escritas soltas com poemas de um poeta ou mesmo em 'livros' de poemas com o conjunto de sua produção".

De acordo com Mongelli (2009), o galego-português tornou-se a língua de predileção dos trovadores em um movimento iniciado na primeira metade do século XII, quando, atravessando os Pirineus, poetas e jograis da Provença passaram a visitar algumas cortes régias peninsulares. Segundo a autora, Santiago de Compostela, na Galiza, foi um centro de peregrinações de grande popularidade, atraindo romeiros de diversas regiões.

Segundo Michaëlis de Vasconcelos (1946 [1912-1913], p. 14), eram raros os documentos escritos em português no final do século XII. Para a autora, somente a partir do século XIII (de 1250 em diante), esses textos começam a aparecer com maior frequência. Além disso, a estudiosa declara que a língua dos poucos documentos remanescentes do final do século XII, embora fosse já a portuguesa, ainda era "bem caracterizada pelas suas feições especiais", apresentando algumas formas do "latim bárbaro"².

Sobre este assunto, Mattos e Silva (2006, p. 38) considera uma questão problemática a que se refere à datação dos primeiros documentos escritos em português. A autora menciona que o padre Avelino de Jesus da Costa ${ }^{12}$, ao publicar as duas cópias remanescentes do Testemunho de Afonso II, coloca em questão a datação dos documentos não literários até então considerados os mais antigos em português. De acordo com Mattos e Silva (2006, p. 38), tal fato

[...] demonstra que aqueles antes considerados os mais antigos - o Auto de Partilhas e o Testamento de Elvira Sanches não são, respectivamente, de 1192 e 1193, mas ambos dos fins do século XIII, sendo assim, os seus originais em latim, dos fins do século XII. Também demonstra que a Notícia do Torto, que se datava de 1211, deve ser situada entre 1214-1216.

Para a autora, estes documentos, entretanto, aparecem como extemporâneos ou temporãos, pois só a partir de 1255 é que voltam a aparecer documentos jurídicos escritos não mais em latim, e "daí para adiante eles se multiplicam, até que no reinado de D. Dinis (1279-1325) a língua portuguesa se torna a língua oficial de Portugal e substitui o latim na documentação jurídica" (MATTOS E SILVA, 2006, p. 38).

2 Michaëlis de Vasconcelos (1946, p. 13) usa a expressão "latim bárbaro" para designar a língua em que foram escritos certos tipos de documentos da região Lusitânia entre os séculos IX e XII. Segundo a autora, esses textos consistem em documentos públicos, cuja língua não corresponde nem ao latim vulgar e nem ao português propriamente dito. 
Borges (2008, p. 31) afırma que, em qualquer estudo de caráter histórico, há uma tendência para a delimitação das épocas durante as quais o objeto de estudo, neste caso em particular a língua, apresenta certa coerência. Segundo a autora, quando a língua é dividida em períodos, estes não são traduzidos em datas precisas, pois há mudanças linguísticas ocorrendo, embora em ritmos diferentes, de acordo com a época. Por isso, "há um consenso entre os autores em não escolher datas, mas sim períodos de separação longos, temporalmente" (BORGES, 2008, p. 31).

Câmara Jr. (1976 [1970], p.18) divide o português em período "arcaico", que perdura até o século XV, e um período posterior denominado de "moderno". Essas duas fases distinguem-se por traços característicos de natureza fonológica, gramatical e lexical bem demarcados. Há ainda um período denominado de "clássico", que vai do século XVI ao XVII, e outro "pós-clássico", que abrange os anos subsequentes.

Durante o período que compreende os séculos IX e XII, já existiam, segundo Borges (2008, p. 34), "fenômenos específicos que singularizavam a área linguística galegoportuguesa em relação a outros romances hispânicos". Esse período é considerado por alguns filólogos de proto-histórico. Porém, é no final do século XII e começo do século XIII que se situa o início do PA (Português Arcaico), como afirma Williams (1973 [1938], p. 27):

Os mais antigos documentos em português aparecem pelo fim do século XII e marcam o começo histórico do Português Arcaico. Durante quatro séculos a língua sofreu muitas modificações. [...] Pelo fim do século XVI, quase todas as características distintivas do Português Arcaico haviam desaparecido; a língua se tornava, no essencial, a mesma de hoje em dia.

Sobre o que diz respeito ao surgimento da língua portuguesa, pesquisadores são unânimes em afırmar que, com a diversificação do latim ao longo da história, nos deparamos com o surgimento das chamadas línguas românicas. Williams (1973 [1938], p. 25) nos apresenta as causas das transformações das línguas românicas:

A diferenciação do latim vulgar de uma região para outras, que finalmente resultou na sua transformação nas diversas línguas românicas crê-se ter sido devida às causas seguintes: a) o relativo isolamento geográfico dos grupos entre si; b) o desenvolvimento de unidades políticas separadas; c) a variação cultural e as circunstâncias educacionais ou o período de romanização e diferenças dialetais na língua dos colonos itálicos; f) os substratos lingüísticos originais; g) os superstratos lingüísticos subsequentes.

Mattos e Silva (2001, p. 17) faz uma enumeração dos aspectos extralinguísticos mais importantes que determinam o fim do PA, mas ressalta que esses dados devem ser levados em consideração enquanto não existir um estudo estrutural da língua: 
[...] são acontecimentos extralingüísticos que são tomados como balizas para marcar o fim do período arcaico, tais como: o surgimento do livro impresso, em substituição aos manuscritos medievais nos fins do século XV e suas conseqüências culturais; o incremento da expansão imperialista portuguesa no mundo, que se refletiu na sociedade portuguesa européia pelo contato com novas culturas e novas línguas, provocando, certamente, reflexos na língua portuguesa no seu processo de variação e mudanças; o delineamento de uma normatização.

Neste sentido, é muito relevante realizar a delimitação e a caracterização do PA, com o objetivo de evidenciar aspectos históricos que possam ter influenciado a composição de textos remanescentes do período medieval e que são fundamentais para o estudo historiográfico da língua. Assim, para a realização deste estudo, foram levadas em consideração as 450 Cantigas de Santa Maria, textos poéticos remanescentes do galegoportuguês medieval, a partir de edições interpretativas e fac-similadas.

\subsection{A relevância das composições líricas para o estudo historiográfico}

Massini-Cagliari e Cagliari (2001, p. 83) afırmam que é muito relevante a consideração da poesia em uma análise linguística de línguas antigas. Para os autores, a tradição da análise poética tem mostrado que a poesia pode revelar a duração das sílabas, a localização do acento e pausas (cesuras) e um valor melódico/rítmico de natureza acústica. Com base na observação desses fatos, desenvolveram-se, dentro dessa tradição de análise poética, vários métodos de descrição.

Para Mattos e Silva (2001, p. 32), os documentos linguísticos fornecidos pelas líricas medievais galego-portuguesas são muito ricos, pois, através dos dados obtidos e a partir das considerações desses textos, encontramos pontos essenciais para o conhecimento do léxico e de outros aspectos da língua:

O fato de serem poemas de estrutura formal em versos rimados os torna fundamentais, no que concerne a estudos de história da língua, para o conhecimento de fatos fonéticos desse período, como sejam, por exemplo, questões referentes aos encontros entre vogais (hiatos/ditongos), ao timbre vocálico (abertura e fechamento), vogais e ditongos nasais/orais. A morfologia tanto a nominal como a verbal também tem nessa documentação uma fonte fundamental. A questão da sintaxe aí representada deve ser considerada, tendo sempre presente que o caráter excepcional e variável é essencial na construção poética.

De acordo com vários estudos e discussões acerca da relação entre os dados contidos nos documentos e a língua indiretamente representada pela língua escrita, é possível chegar ao português falado da época. Mattos e Silva (2001, p. 39) nos aponta esta possibilidade, 
pois não havia um controle gramatical normativo naquele período, o que faz com que os textos daquela época apresentem variações constantes, fato que é indicador de usos da fala:

\begin{abstract}
[...] sendo a documentação escrita que permanece, e sendo essa uma representação convencional da fala, desta teremos nos documentos um reflexo que permite tirar conclusões até certo ponto seguras, no nível fônicomórfico, já que, não havendo então uma normatização ortográfica, a análise da variação da escrita oferece indícios para alguma percepção da voz. Do mesmo modo, se o que está escrito procura espelhar a voz e esta nos falta, pelo escrito se pode depreender, embora não integralmente, a língua no seu uso primeiro, em qualquer dos níveis em que se pode estruturá-la: fônico, mórfico, sintático, discursivo.
\end{abstract}

Além dos poemas trovadorescos, existem outros gêneros textuais que também foram preservados ao longo dos anos. Tratam-se de arquivos jurídicos, os chamados documentos notariais, que apresentam como temas doações de terras, testamentos, compra ou venda de imóveis, inventários, etc. Há também os forais ou costumes, cujo conteúdo reúne leis locais que estabeleciam as normas disciplinares em relação aos habitantes.

Segundo Mattos e Silva (2006, p. 38), esses textos são importantes para o conhecimento do PA, pois são significativos e informativos, além de trazerem as datas em que foram exarados. Porém, no que concerne ao conhecimento da Sintaxe, tais textos não são valiosos, em função da estrutura formular ser muito restrita, "às vezes alatinada, natural a este tipo de texto que segue modelos da tradição jurídica latina" (MATTOS E SILVA, 2006, p. 39).

\title{
2 As Cantigas de Santa Maria - suas relevâncias
}

Leão (2002) mostra que foi em um espaço de efervescência cultural que nasceram as Cantigas de Santa Maria, uma coleção de 420 cantigas religiosas em louvor da Virgem Maria (das quais 356 são narrativas e relatam milagres marianos, e as demais, exceto a introdução e os prólogos, são de louvor ou se referem às festividades marianas), com notação musical (salvo o poema introdutório e algumas outras cantigas em que a notação musical não chegou a ser acrescentada, apesar de haver espaço previsto para esta finalidade).

Parkinson (1998) afırma que a intenção dessa coletânea sempre foi a de louvar a Virgem e aumentar a devoção a ela; por este motivo, todas as cantigas são na verdade de louvor e exaltam a Mãe de Deus. Filgueira Valverde (1985) ressalta que diversos milagres marianos foram recolhidos de igrejas e santuários europeus, sobretudo franceses e ibéricos, e são de fonte confirmada e bem conhecida, mas muitos relatos ainda hoje são desconhecidos e provavelmente apenas orais. 
As Cantigas de Santa Maria, segundo Castro (2006) e Leão (2007), além de serem um precioso documento linguístico e uma verdadeira obra de arte, constituem uma valiosa fonte histórica da vida cotidiana e do imaginário popular de toda cultura Ibérica, na Idade Média:

[...] elas nos falam não só da vida religiosa, mas da vida em toda a sua complexidade, constituindo talvez o mais rico documento para o conhecimento da mentalidade, dos costumes, das doenças, das profissões, da prostituição, do jogo, dos hábitos monásticos, de todos os aspectos enfim do cotidiano medieval da Ibéria. (LEÃO, 2007, p. 153).

As CSM foram elaboradas em galego-português e atribuídas a Dom Afonso X de Castela, 0 Sábio, com a colaboração de trovadores, músicos, desenhistas e miniaturistas que acolhia em sua corte, tendo sido produzidas principalmente no final de sua vida, enquadrando-se na fase denominada "arcaica" do desenvolvimento do português. Segundo Mattos e Silva (1989, p. 15), essa fase tem seus limites entre os séculos XIII e XV:

[...] o lugar de produção coincide com os limites históricos em que o português era usado como língua escrita - e isso não se restringe aos limites da nação portuguesa, como se sabe - e os informantes são os produtores (autores, tradutores, copistas) dos documentos que, elaborados naqueles limites cronológicos, chegam até o pesquisador atual.

Segundo Bertolucci Pizzorusso (1993, p. 144), as cantigas marianas são uma obra para ser vista e ouvida, na qual "uma milagrística por imagens junta-se à milagrística em versos". Na percepção de Mettmann (1986, p. 8), justamente por apresentarem um perfeito equilíbrio entre texto, melodias e miniaturas ocupam um lugar importante na literatura medieval galego-portuguesa.

De acordo com Leão (2007, p. 27), as CSM abordam em seus textos, pelo menos nas cantigas que relatam os milagres realizados pela virgem, "a verdadeira comédia humana do século XIII". Ressaltamos que de acordo com Aulete (2014), neste contexto, definimos comédia como o complexo das vivências, fatos, alegrias etristezas, conquistas e fracassos etc., que se desenvolve durante a vida (comédia da vida). Lapa (1981, p. 205) também já havia feito esta observação acerca do valor documental das cantigas marianas:

Nela [nessa comédia humana] todas as classes sociais se vestem à sua maneira, falam a sua línguaguem, denunciam os sentimentos: o papa enamorado, o rei enfermo e devoto, o rico-homem soberbo e aventureiro, o mercador ganancioso, o judeu sórdido e perserguido, o mouro cavaleiro, o taful blasfemo, o jogral remedador, a monja voluptuosa e pecadora, e até mesmo o menino inocente e dadivoso. 
Em relação aos aspectos linguísticos, Leão (2007, p. 152-153) ressalta a riqueza lexical das CSM e afirma que:

Do ponto de vista do léxico, as Cantigas apresentam uma riqueza imensa (como também, embora em menor grau, as cantigas de escárnio), pois não se limitam à tópica amorosa como as cantigas de amigo e de amor. Ao contrário, elas nos falam não só da vida religiosa, mas da vida em toda a sua complexidade, constituindo talvez o mais rico documento para o conhecimento da mentalidade, dos costumes, das doenças, das profissões, da prostituição, do jogo, dos hábitos monásticos, de todos os aspectos enfim do quotidiano medieval na Ibéria.

Além desses fatores apontados por Leão (2007), outra característica das cantigas é que elas são acompanhadas por iluminuras (desenhos em forma de miniatura que representam em geral o conteúdo narrado na cantiga). Castro (2006, p. 44) também traz observações sobre as iluminuras e as compara com vitrais, afırmando que "podemos até pensar que as riquíssimas iluminuras que acompanham originalmente os textos e as notações musicais servem-lhe como vitrais, que trazem um encanto inigualável às construções religiosas". Costa (2006, p. 23) afirma que é a partir dessas características (a poesia, a música e a gravura) que podemos dizer, com toda a certeza, que as cantigas religiosas constituem uma das fontes mais ricas de informação a respeito da cultura geral do período medieval.

Sobre a riqueza do vocabulário e do estilo em geral das CSM, Leão $(2002$, p. 3) nos chama atenção para uma diversidade muito grande de tema, não retratando apenas a vida religiosa, e sim também a vida em toda sua complexidade. Segundo a autora, essa complexidade teve repercussão na linguagem.

Filgueira Valverde (1985,), também se referindo à escolha reflexiva de cada vocábulo usado por Afonso X, afirma que havia uma busca constante de novos assuntos e fórmulas rítmicas para expressá-los, e certa preocupação com cada detalhe da narração poética ou histórica. Leão (2002) ainda afırma que o galego-português literário do século XIII apresentava uma unidade, mas certamente já começava a fragmentar-se na língua oral, e isso já era percebido na linguagem literária. Para a autora, uma prova disso é que a linguagem utilizada nos cancioneiros profanos se encaminha para o português, enquanto a linguagem das CSM, no que diz respeito à morfologia e à fonologia, tende mais para o padrão galego.

Porém, alguns autores, em relação a esse aspecto, discordam de Leão (2002). Gonçalves (1985) afirma que a linguagem dos cancioneiros e das CSM é a mesma, o galegoportuguês. As autoras (cf. GONÇALVES, 1985 e LEÃO, 2002) entendem por lírica galegoportuguesa um grupo de 1980 textos de assunto profano, que foram transmitidos por três cancioneiros, e 420 textos religiosos, as chamadas Cantigas de Santa Maria. 
Para Gonçalves (1985, p. 18-19), todos esses textos foram escritos numa língua com características bastante uniformes, o galego-português, em um período que vai de finais do século XII à segunda metade do século XIV.

De acordo com Massini-Cagliari (2005), as diferenças fonológicas encontradas entre esses dois tipos de discurso não são de tipologia dos fenômenos, mas de frequência. A autora ainda ressalta que as CSM possuem um nível de formalidade de expressão muito maior do que as cantigas profanas, "dada a tendência mais latinizante do discurso religioso, que, embora composto em galego-português, se refere a um universo em que dominava o latim, língua oficial da Igreja" (MASSINI-CAGLIARI, 2007, p.113).

\section{As Cantigas de Santa Maria e os aspectos morfológicos}

A lírica medieval portuguesa é muito rica e sua análise pode revelar aspectos importantes da língua portuguesa, inclusive os associados aos aspectos morfológicos. Dentre os estudos realizados com os poemas medievais, podemos destacar o trabalho de Favaro (2016), que a partir da análise da estrutura morfológica das formas verbais imperativas em PA, observa alguns aspectos da evolução da língua portuguesa no que se refere às mudanças que ocorrem com os verbos, em especial com o modo imperativo, focalizando seus estudos no momento arcaico da língua.

Favaro (2016) escolheu analisar textos poéticos remanescentes do galego-português medieval, e um dos aspectos decisivos para a determinação dos textos a serem estudados foi verificar se havia registros de interação entre os interlocutores. Como o período temporal abrangido situa-se no século XIII, de todos os documentos remanescentes deste período e que chegaram até nós, através dos cancioneiros medievais, as líricas profana e mariana se enquadram no tipo de texto que favorece o uso do imperativo porque, muitas vezes, retratam interações entre interlocutores, o que não é verificado nos demais tipos de gêneros textuais da época, uma vez que são documentos oficiais ou de natureza jurídica.

Assim, com o intuito de encontrar tais formas verbais, Favaro (2016) considerou os textos poéticos para a observação de situações que proporcionassem diálogos, sobretudo os reproduzidos através do discurso direto, pois o uso do imperativo só ocorre em contextos de interação direta (diálogos) entre os interlocutores. De acordo com Matos e Silva (2006), através da variação gráfica presente nos documentos trovadorescos, podemos depreender indícios de realizações fônicas conviventes e pela variação morfológica e sintática, são percebidas possibilidades estruturais em uso naquele período, proporcionando o tipo de análise proposta por Favaro (2016). 
Peña (1973) também enfatiza, baseada nos estudos de Marquês de Valmar (1889), que a linguagem das cantigas não era o galego popular, mas sim o galego erudito que adquiriu (sem perder a essência do dialeto português primitivo), o caráter de idioma literário. Apesar disso, como o período temporal abrangido por este artigo situa-se entre os séculos XIII e $\mathrm{XVI}$, de todos os documentos remanescentes desta época e que chegaram até nós, através dos cancioneiros medievais, as líricas profana e mariana se enquadram no tipo de texto que favorece o uso das formas imperativas, uma vez que há registro de fala muito próximo ao da linguagem popular e cotidiana (tanto da corte quanto da população local), com a presença de diálogos entre as personagens, ao longo das cantigas, nos quais aparecem ordens e pedidos, como pode ser observado nos exemplos (1) e (2):

(1)

Chorando dos ollos mui de oraçon,

Ile diss': "Ai Sennor, oe mi oraçon [...]". (CSM 21, v.15-16)

(2)

E o maestre da nave diss' a un seu ome: "Vai, coz

carn' e pescado do meu aver, que te non cost' hũa noz". (CSM 5, v.147-148)

Favaro (2016) mapeou 119 verbos regulares nas 450 CSM, conjugados no imperativo na $2^{a}$ pp e na $2^{a}$ ps. A metodologia baseou-se no mapeamento das formas verbais do modo imperativo nas Cantigas de Santa Maria. Contamos também com glossários, vocabulários, dicionários e, especialmente, o glossário de Mettmann (1972), como auxílio na categorização das formas verbais. Depois de mapeadas as ocorrências em todas as cantigas do corpus, de acordo com os procedimentos descritos acima, foram montados quadros, nos quais as formas verbais encontradas são classificadas por conjugação e número-pessoa, e tabelas, que trazem a quantificação dos dados.

De acordo com a autora, nas CSM ocorre o uso expressivo da $2^{\mathrm{a}}$ ps em relação à $2^{\mathrm{a}}$ pp, num total de 76,0\% e 24,0\% de ocorrência respectivamente. Este fenômeno ocorre, pois, a presença da $2^{a}$ pp ficou restringida aos episódios que narram acontecimentos que envolvem pessoas da nobreza, familiares do rei ou quando a cantiga é lavrada por Afonso X. Fazendo a representação morfológica das formas conjugadas no imperativo e comparando-as com a sua conjugação no indicativo e no subjuntivo, temos a seguinte estrutura: 
(3) Verbo Levar (PA) = Levar (PB)

Imperativo: levade

\begin{tabular}{|l|l|l|l|}
\hline Radical & $\mathrm{VT}$ & $\mathrm{MT}$ & $\mathrm{NP}^{3}$ \\
\hline lev & $a$ & $\varnothing$ & de \\
\hline
\end{tabular}

Presente do Indicativo: levades

\begin{tabular}{|l|l|l|l|}
\hline Radical & VT & MT & NP \\
\hline lev & $a$ & $\varnothing$ & des \\
\hline
\end{tabular}

Presente do Subjuntivo: levedes

\begin{tabular}{|l|l|l|l|}
\hline Radical & VT & MT & NP \\
\hline lev & $a(e)$ & $\varnothing$ & des \\
\hline
\end{tabular}

(4) Verbo Acorrer (PA) = Acordar em, resolver, decidir (PB)

Imperativo: acorre

\begin{tabular}{|l|l|l|l|}
\hline Radical & VT & MT & NP \\
\hline acorr & $e$ & $\varnothing$ & $\varnothing$ \\
\hline
\end{tabular}

Presente do Indicativo: acorres

\begin{tabular}{|l|l|l|l|}
\hline Radical & VT & MT & NP \\
\hline acorr & $e$ & $\varnothing$ & $s$ \\
\hline
\end{tabular}

Presente do Subjuntivo: acorras

\begin{tabular}{|l|l|l|l|}
\hline Radical & VT & MT & NP \\
\hline acorr & e (a) & $\varnothing$ & $s$ \\
\hline
\end{tabular}

3 Leia: VT (vogal temática), MT (desinência de modo-pessoa) e NP (desinência de número e pessoa); 
Ao realizar a divisão dos dados em morfemas, notamos que as formas verbais mapeadas no corpus são quase idênticas às formas do presente do indicativo, contudo sem o morfema -s final. Este tipo de fenômeno ocorre, pois, quando formamos o imperativo, a segunda pessoa tanto do singular quanto do plural coincide com as formas do presente do indicativo, e isto já acontecia desde o latim, de acordo com os estudos de Ernout (1945) e Faria (1958).

Não foi mapeada qualquer ocorrência em que tivéssemos uma forma morfologicamente idêntica para representar o imperativo, o presente do indicativo e o presente do subjuntivo ao mesmo tempo. Ao compararmos a ocorrência com seu correspondente no presente do indicativo e no presente do subjuntivo, vemos que cada forma mantém uma estrutura morfológica específica, uma vez que a diferença entre tais estruturas está concentrada no morfema de NP.

Após a realização da análise dos dados coletados nas CSM, Favaro (2016) mostra que o modo imperativo, hoje, apresenta dois tipos de flexões para a $2^{a}$ pessoa: a) uma originária a partir da $2^{a}$ pessoa e extraída do presente do indicativo, sem o morfema -s de NP, e b) outra originária historicamente da $3^{\mathrm{a}} \mathrm{ps}$, com o surgimento da forma pronominal você, em meados do século XVIII.

Para explicar esse fenômeno, no português, Faraco (1982) reforça que as mudanças morfológicas que o modo imperativo vem sofrendo se dão em decorrência das transformações sociais, em particular, da mudança das formas de tratamento. De acordo com o autor, a heterogeneidade social e fatores ligados à economia do país resultaram na criação e na difusão de formas pronominais de tratamento diferentes das utilizadas pelas pessoas até os séculos XIV e XV.

Faraco (1982) ainda ressalta que a população portuguesa que foi enviada para colonizar o Brasil, em meados do século XV, não tinha origem nobre e a língua trazida pelos primeiros habitantes europeus não era culta. Nesse sentido, desde o início da ocupação lusitana em terras brasileiras, o pronome vós era raramente usado e o "uso de diferentes formas relativas a Vossa Mercê para se referir à $2^{a}$ pessoa era largamente usado: vosmercê, vassuncê, mecê, vânce, ocê e você" (FARACO, 1982, p. 201).

Em função da alteração dos pronomes de $2^{a}$ pessoa no PB, diversas mudanças foram ocorrendo para que o sistema linguístico pudesse entrar em equilíbrio, dentre as quais podemos citar a reformulação do sistema de conjugação verbal. Porém, observando as CSM, podemos afirmar que no PA ainda havia o uso do modo imperativo como distinto do indicativo, já que as relações de tratamento ainda eram bem definidas e as estruturas morfológicas das formas verbais ainda eram preservadas, como podemos observar no exemplo (5): 
(5) i. Situação de respeito e superioridade: Fala proferida por um Conde a uma senhora.

O Conde, poi-la livrou dos vilãos, disse-lle: "Senner,

dizede-m' ora quen sodes ou dond [...]". (CSM 5, v.75-76)

dizede $=$ imperativo do verbo dizer conjugado na $2^{\mathrm{a}} \mathrm{pp}$.

ii. Situação de intimidade ou inferioridade: Fala proferida de um marinheiro a outro membro da embarcação.

E o maestre da nave diss' a un seu ome: "Vai, coz

carn' e pescado do meu aver, que te non cost' hũa noz". (CSM 5, v.147-148)

$\mathbf{v a i}=$ imperativo do verbo ir conjugado na $2^{\mathrm{a}} \mathrm{ps}$.

coz-= imperativo do verbo cozer (cozinha) conjugado na $2^{\mathrm{a}} \mathrm{ps}$.

Favaro (2016) ressalta que o uso do pronome você e das formas variantes para expressar o modo imperativo "é resultante da história de formação de nosso país" (BORGES, 2004, p. 24). Segundo Borges (2004), a fragilidade do modo imperativo pode vir da falta de sua produtividade funcional, uma vez que existem outras formas com a mesma função, inclusive o uso do presente do indicativo.

Essas afirmações foram possíveis graças à análise do gênero lírico medieval que proporcionou a ocorrência de contextos favoráveis ao uso de formas verbais em situações de ordem e/ou pedido. Estudando a formação das conjugações verbais da língua portuguesa, em seu estágio "inicial" (ou melhor, no estágio temporal em que primeiramente começa a ser referida com este nome), Favaro (2016) contribui para a observação de mudanças linguísticas que ocorreram na constituição do sistema verbal ao longo dos anos.

\section{Conclusões}

O intuito deste artigo foi ressaltar a importância do uso da lírica medieval galegoportuguesa para os estudos linguísticos do português. Analisando este tipo de gênero textual, podemos chegar à descrição dos componentes linguísticos, de modo especial os componentes morfológicos da língua na época trovadoresca, formulando hipóteses de mudanças linguísticas ocorridas desde as origens do português até os dias de hoje.

Assim, estudar as CSM é reafirmar o postulado de Mattos e Silva (2006) e reforçar esta ideia de Mettmann (1986): as CSM ocupam um lugar privilegiado na literatura medieval e, sem dúvida, para seu régio "autor", "compor músicas" e "pintar" não eram menos importante do que os hábitos de "contar", "trovar" e "rimar" de sujeitos da época. 
Portanto, as cantigas medievais religiosas portuguesas nos direcionaram à percepção da relevância de diversos aspectos da língua, fundamentais para a elaboração de um panorama mais rico sobre fenômenos linguísticos da língua portuguesa e, com isso, há um melhor conhecimento da história do nosso próprio idioma.

\section{REFERÊNCIAS}

AULETE, C. Dicionário contemporâneo da língua portuguesa. Rio de Janeiro: Delta, 2014.

BERTOLUCCI PIZZORUSSO, V. Afonso X. In: LANCIANI, G.; TAVANI, G. (org.). Dicionário da literatura medieval galega e portuguesa. Lisboa: Caminho, 1993. p. 142-146.

BORGES, P. R. Estruturas Morfofonológicas das Formas Futuras nas Cantigas de Santa Maria. 2008. Tese (Doutorado em Linguística e Língua Portuguesa) - Faculdade de Ciências e Letras, Universidade Estadual Paulista "Júlio de Mesquita Filho", Araraquara, 2008.

BORGES, P. R. Formas verbais imperativas em tiras de jornais paulistas. 2004. Dissertação (Mestrado em Linguística e Língua Portuguesa) - Faculdade de Ciências e Letras, Universidade Estadual Paulista "Júlio de Mesquita Filho", Araraquara, 2004.

CÂMARA JR., J. M. História e estrutura da língua portuguesa. Rio de Janeiro: Padrão, 1979 [1976].

CASTRO, B. M. As Cantigas de Santa Maria: um estilo gótico na lírica ibérica medieval. Niterói: EdUFF, 2006.

COSTA, D. S. da. Estudo do Acento Lexical no Português Arcaico por meio das Cantigas de Santa Maria. 2006. Dissertação (Mestrado em Linguística e Língua Portuguesa) Faculdade de Ciências e Letras, Universidade Estadual Paulista "Júlio de Mesquita Filho", Araraquara, 2006.

ERNOUT, A. Morphology Historique du Latin. Paris: C. Klincksieck, 1945.

FARACO, C. A. The imperative sentence in Portuguese: a semantic and historical discussion. 1982. Tese (Doutorado) - University of Salford, Salford, 1982.

FARIA, E. Gramática superior da Língua Latina. Rio de Janeiro: Livraria Acadêmica, 1958. 
FAVARO, G. Estudo das formas verbais do modo imperativo nas Cantigas de Santa Maria. 2016. Tese (Doutorado em Linguística e Língua Portuguesa) - Faculdade de Ciências e Letras, Universidade Estadual Paulista "Júlio de Mesquita Filho", Araraquara, 2016.

FILGUEIRA VALVERDE, J. Introducción. In: ALFONSO X EL SABIO. Cantigas de Santa María: Códice Rico de El Escorial. Madrid: Castalia, 1985. p. XI-LXIII.

GONÇALVES, E. Apresentação crítica. In: GONÇALVES, E.; RAMOS, M. A. A lírica galegoportuguesa (textos escolhidos). 2. ed. Lisboa: Editorial Comunicação, 1985.

LAPA, M. R. Fernão Lopes e os cronistas In: LAPA, M. R. Lições de literatura portuguesa: época medieval. Coimbra: Universidade de Coimbra, 1981. p. 369.

LEÃO, Â. V. Cantigas de Santa Maria de Afonso X, o Sábio: aspectos culturais e literários. Belo Horizonte: Veredas \& Cenários, 2007.

LEÃO, Â. V. Questões de linguagem nas Cantigas de Santa Maria, de Afonso X. Ensaios. Associação Internacional de Lusitanistas (AIL). 2002. Disponível em: http://www.pucrs. br/fale/pos/ail/leao01.htm. Acesso em: 17 jan. 2005.

MARCUSCHI, L. Produção textual, análise de gêneros e compreensão. São Paulo: Parábola Editorial, 2008.

MASSINI-CAGLIARI, G. Legitimidade e identidade: da pertinência da consideração das Cantigas de Santa Maria de Afonso X como corpus da diacronia do Português. In: MURAKAWA, C. A. A. de; GONÇALVES, M. F. (org.). Novas contribuições para o estudo da história e da historiografia da língua portuguesa. São Paulo/Araraquara: Cultura Acadêmica/ Laboratório Editorial da FCL/UNESP-Araraquara, 2007. v. 1, p. 101-126.

MASSINI-CAGLIARI, G. A música da fala dos trovadores: estudos de prosódia do português arcaico, a partir das cantigas profanas e religiosas. 2005. Tese (Livre Docência em Linguística) - Faculdade de Ciências e Letras, Universidade Estadual Paulista "Júlio de Mesquita Filho", Araraquara, 2005.

MASSINI-CAGLIARI, G. De sons de poetas ou estudando fonologia através da poesia. Revista da Anpoll, São Paulo, Humanitas Publicações - FFLCH / USP, n. 5, p. 77-105, 1998.

MASSINI-CAGLIARI, G.; CAGLIARI, L. C. Fonética. In: MUSSALIM, F.; BENTES, A. C. (org.). Introdução à Linguística: domínios e fronteiras. São Paulo: Cortez, 2001. v. 1, p. 105-141. 
MATTOS E SILVA, R. V. O Português Arcaico: fonologia, morfologia e sintaxe. São Paulo: Contexto, 2006.

MATTOS E SILVA, R. V. O português arcaico: fonologia. São Paulo: Contexto, 2001.

MATTOS E SILVA, R. V. Estruturas Trecentistas: elementos para uma gramática do português arcaico. Lisboa: Imprensa Nacional - Casa da moeda, 1989.

METTMANN, W. Cantigas de Santa María (cantigas 1 a 100): Alfonso X, el Sabio. Madrid: Castalia, 1986 (volume I).

METTMANN, W. Glossário. In: AFONSO X, O SÁBIO. Cantigas de Santa Maria. Coimbra: Universidade, 1972, v. IV: Glossário.

MICHAËLIS DE VASCONCELOS, C. Lições de Filologia Portuguesa (segundo as preleções feitas aos cursos de 1911/12 e de 1912/13) seguidas das Lições Práticas de Português Arcaico. Rio de Janeiro: Martins Fontes, 1946 (1912-1913).

MONGELLI, L. M. Fremosos cantares: antologia lírica medieval galego-portuguesa. São Paulo: Editora WMF Martins Fontes, 2009. p. 21-46.

PARKINSON, S. As Cantigas de Santa Maria: estado das cuestións textuais. Vigo: Anuario de estudios literarios galegos, 1998. p. 179-205.

PEÑA, M. Affonso el Sabio. Antología com estudios preliminares y un vocabulario. México: Porrúa, 1973.

WILLIAMS, E. B. Do Latim ao Português. 3. ed. Rio de Janeiro: Tempo Brasileiro, 1973 [1938]. 